\title{
The brief history of game theory and the dissemination in China
}

\author{
YANG Fan ${ }^{1}$, ZHU Chun-hong ${ }^{1,2}$ \\ (1. School of Economics, Tianjin Polytechnic University, Tianjin 300160, China; \\ 2. School of Economics, Nankai University, Tianjin 300071, China)
}

\begin{abstract}
After the year of 1944, Von Neumann and Morgenstern published the book "Theory of Games and Economic Behavior", the game theory had gradually become an emerging discipline. At present, game theory has already penetrated to every industry and widespread application in economy, politics and military and so on. The paper introduces the history and the developed situation of game theory about the foreign and domestic state.
\end{abstract}

Key words: game theory; development; summary

\section{The origin of game theory}

What is game theory? As the old saying, the humans' affairs like a chess. In our lives, each person is similar to a chess player; and his behavior is similar to play chess on the invisible chessboard. Smart players consider and overwhelm each other, everybody struggle to win. The game theory is on the research that how the players to play. Although game theory is relevant to games such as poker or bridge, most research in game theory focuses on how groups of people interact.

Actually, there is no recognized answer to the beginning of game theory's history. According to the criterions which contains the thought of game theory and use it to the policy, there is a glorious history of game theory. About 2000 years ago in the ancient China, there was the story of "Horse racing between QI Wei-wang and TIAN Ji"; and about 1500 years ago, Babylon proposed "the marital contract" in the code of Judaism etc. So, it is early for the human beings to use the gambling thought into the social and practice life.

In 1838 Gournot carried on the model that the oligarchs competed each other through the output decision-making, it can be regarded as the research beginning of game theory, but Gournot had not used the word "game", and did not solve more economic problems by using this method. In 1881 Edgeworth proposed the "contract curve", it was also the early idea of game theory.

To the early 20th century, the research on chess by Zermelo and Borel can represent the start of game theory, Zermelo firstly pointed out the "Backward Induction Procedure", and during 1921 to 1927, Borel proposed the minima result in two people's game. Von Neumann and Morgenstern given the expansion game definition in 1928, and had proven that the two people zero-sum game with limited strategy has a determination result (XIE Shi-yu, 2005). The miniature of game theory had formed, but these theories had not completed the system of game theory, until Von Neumann and Morgenstern published their book "Theory of Games and Economic Behavior" in 1944 (Von Neumann and Morgenstern, 1944), the game theory was truly born. The book gives the general frame, the concept terminology and the indication method of game theory, and proposed the systematic theory.

YANG Fan, graduate student of School of Economics, Tianjin Polytechnic University, research field: industrial economics.

ZHU Chun-hong, Ph.D. candidate of School of Economics, Nankai University, Master supervisor of School of Economics, Tianjin Polytechnic University; research field: industrial economics. 


\section{The development of game theory}

The publication of the book "Theory of Games and Economic Behavior" represented the production of game theory, but at that time it was not very mature, the researchers were almost mathematicians; the content and the scope were quite limited; moreover, the overall influence was also very small.

From the 1940s to the early 50s, the game theory had a further development. In 1950, Nash proposed that it should expand the game theory to the aspect of non-vanishing-the concept of "Nash equilibrium" and the Nash theorem of its existence; these had developed the basic theory of non-cooperation game theory which was the core of Nash equilibrium. Then in 1950 Melvin Dresher and Merrill Flood firstly carried on the "Prisoner's Dilemma" experiment in the research institution established in the United States Air Force.

After the middle 1950s, the game theory researchers were not restricted only in mathematicians, but many economists and statisticians also had made contribution to the game theory progress. The most famous people were Selten and Harsanyi. The former proposed the Subgame Perfect Nash Equilibrium which had conducted the developing research to dynamic game; he also proposed the concept of Trembling Hand Perfect Equilibrium in 1975. The latter proposed the concept Bayesian Nash Equilibrium about incomplete information games and had a thorough research. Harsanyi and Selten also discussed the general theory of equilibrium choice together. In addition, Scarf's research on equilibrium calculation, Aumann's axiomization to the knowledge, Kreps and Wilson's research on the sequential equilibrium, Tirole's discussion about organization of enterprise principle, and the development of Evolutionary Game Theory were all the important achievements of game theory. (HOU Pei-ding, 2004)

From 1980s to the end of 20 century, the game theory moved toward the mature period, its application was also getting more and more widespread in economic domain. In 1982, John Maynard Smith published "Evolution and the Theory of Games"; in 1988, Harsanyi and Selten proposed the general theory standard in non-cooperation and cooperation game equilibrium choice; in 1991 Fudenberg and Tirole firstly pointed out the concept Perfect Bayesian Equilibrium etc. The mature tendency was reinforced by the twice Nobel Prize. In 1994, three scholars that devoted to the basic study on game theory-Nash, Harsanyi and Selten gained the Nobel Economic Prize together, in 1996, Mirrlees and Vickrey also obtained the same honor by the research on the encourage mechanism.

Since 2000, the game theory's development has been mature day by day, kinds of research results come out in succession. The Nobel 2005 goes to Aumann and Schelling for their enhancing the understanding of conflict and cooperation through game-theory analysis. In 2007, Hurwicz, Maskin and Myerson receive the honor of Nobel Economic Price because their contributions on the mechanism design theory in game theory’s field.

\section{The game theory in China}

There has been about 50 years since the game theory was introduced to China, domestic scholars translated several foreign books of game theory and they also wrote related teaching materials from the late 1950s, and this time also appeared some game theory paper and books. But the dissemination, the application and the research of game theory in China is backward. Until the mid-1990s, scholars published many game theory teaching materials and books which were comprehensive, modern and dominant (SHANG Yu-hong, 2006). According to the research situation of game theory in China it can be divided into three stages: 
(1) Stage of studying and translating the game theory (from early 1950s to late 1960s)

In this stage the research work concentrated on introducing the game theory's early literature and the application of game theory, it had produced a few teaching materials, translations and papers. But the content was mainly restricted about classical content of game theory in early period and had not involved the non-cooperation game content.

(2) Stage of recovering and popularizing the game theory (from late1950s to early 1960s)

In this period the game theory had developed a lot, but the major content was similar to the level in 1950s, it had little relation to the modern game theory. In this decade, scholars presented some foreign translations and books that mainly included: "Versatile Trickster Crosses the threshold to Game theory" (Williams (US), WANG Xue-yi translates, 1984); “Countermeasure Theory and Application” (Tomas (UK), Jin Min and WANG Hui-qing translate, 1988) and so on. The books mainly included: "Interesting Game theory" (TAN Xiang-bo, 1982), “Countermeasure Theory” (WANG Jian-hua, 1986) and “Modern Game theory Method” (ZHANG Kai-sheng, 1991) and so on. These books surmounted the content of countermeasure and some of them had already involved the economical game theory content, but its influence is less, the most domestic scholars placed extra emphasis on mathematical method about countermeasure theory.

(3) Stage of economical game theory expanding rapidly (from mid-1990s until now)

Along with the establishment and development of market economy in Chinese, the game theory is taken as the important part of western economic to introduce, moreover, it develops rapidly and appears massive case studies, particularly in the application aspect of game theory. The primary reason is that the game theory obtains the widespread approval and takes seriously in the recent 30 years in the western economy study, and it occupies the core status. Since the policy of reform and opening up in China, the western economic has become the main object for us to study, the research on game theory is sure to be very important. What's more, the Nobel Prize was give to the game theory several times is also a huge influence.

The game theory get an especially rapid development in China in recent years, the majority of teaching materials and the outstanding translations are completed in this time, related academic organizations and conferences also present one after another. What is most noticeable is the international mathematician congress satellite conference held in Qingdao University, the conference discussed the game theory and its application, numerous top masters of game theory in the world attended this congress, the winner of Nobel economic prize Nash and Aumann were hired for the honorary professors of Qingdao University. These all impels the development of game theory in China.

\section{References:}

HOU Pei-ding. (2004). Introduction of game theory. Hefei: University of Science and Technology of China Press.

SHANG Yu-hong. (2006). The dissemination in China and the present problems. Research on Production, 7.

WANG Wen-ju. (2003). Application of game theory and the development of economics. Beijing: Capital University of Economics and Business Press.

Von Neumann \& Morgenstern. (1944). Theory of games and economic behavior. Princeton: Princeton University Press

XIE Shi-yu. (2005). Economy and game theory. Shanghai: Fudan University Press.

(Edited by Emily and Joy) 